\title{
Assessing the Level of Engagement in Preventive Behaviors and COVID-19 Related Anxiety in Iranian Adults
}

\author{
Amirmalek Nakhaeizadeh ${ }^{1}$, Sepideh Mohammadi ${ }^{2 *}$
}

1. Nursing Student, Student Research Committee, Babol University of Medical Sciences, Babol, Iran

2. Professor Assistant, Department of Nursing, Nursing Care Research Center, Health Research Institute, Babol University of Medical Sciences, Babol, Iran

\begin{tabular}{|c|c|}
\hline Article Info & ABSTRACT \\
\hline $\begin{array}{l}\text { Received: 2020/09/28; } \\
\text { Accepted: 2020/10/19; } \\
\text { Published Online: } 2020 / 12 / 21\end{array}$ & $\begin{array}{l}\text { Introduction: The outbreak of Covid-19 virus is a global crisis and engagement of people } \\
\text { in preventive behavior against COVID-19 has a key role to stop chains of transmission and } \\
\text { adherence to preventive measures can be affected by psychosocial factors. This study aimed at } \\
\text { assessing the relationship between the level of adherence to preventive behaviors and COVID- } \\
19 \text { related anxiety in Iranian adults. }\end{array}$ \\
\hline
\end{tabular}

10.30699/ajnmc.29.2.160

Original Article

Use your device to scan and read the article online

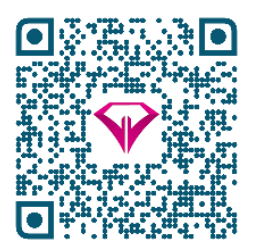

Methods: In this cross-sectional correlational study, 1008 Iranian adults were selected by the convenience sampling method. The online questionnaire of Preventive Behavior against COVID-19 and the Corona Anxiety Scale was sent to research participants. Data were analyzed using descriptive and analytical statistics and SPSS 24 at a significance level of 0.05 .

Results: The average total score of engagement in preventive behavior was $19.47 \pm 2.35$. Some behaviors such as keeping social distance, wearing masks in public places and staying at home was engaged less than other behaviors. The COVID-19 related anxiety was severe in $22.4 \%$ of subjects, moderate in $34.9 \%$ of subjects and low in $42.7 \%$ of subjects. There was a significant relationship between the preventive behaviors and COVID-19 related anxiety $(\mathrm{r}=0.203$, $P<0.001)$. There was a statistically significant difference in the scores obtained from engagement in preventive behaviors and Anxiety Intensity with demographic variables $(P<0.001)$.

Conclusion: Being aware of the general state of preventive behavior of the general public and their experienced anxiety about the disease and identifying at-risk individuals, health policy makers can, shift disease control planning to a greater emphasis on less observed behaviors and positively induce disease anxiety and improve preventive behaviors.

Keywords: COVID-19, Coronavirus, Preventive Behavior, Anxiety

Sepideh Mohammadi, . Professor Assistant, Department of Nursing, Nursing Care Research Center, Health Research Institute, Babol University of Medical Sciences, Babol, Iran. Email: sepidmohamadi@gmail.com

Corresponding Information:

Copyright $(C 2021$, This is an original open-access article distributed under the terms of the Creative Commons Attribution-noncommercial 4.0 International License which permits copy and redistribution of the material just in noncommercial usages with proper citation.

How to Cite This Article:

Mohammadi S, Nakhaeizadeh A. Assessing the Level of Engagement in Preventive Behaviors and COVID19 Related Anxiety in Iranian Adults. Avicenna J Nurs Midwifery Care. 2021; 29 (2):160-170 


\section{بررسى ميزان رعايت رفتارهاى ييشگيرانه و اضطراب ناشى از بيمارى كوويد9ا در جمعيت بزرَسال ايران اميرمالك نخعى زاده '، سييده محمدى "}

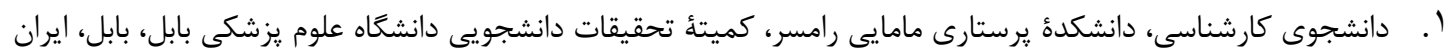

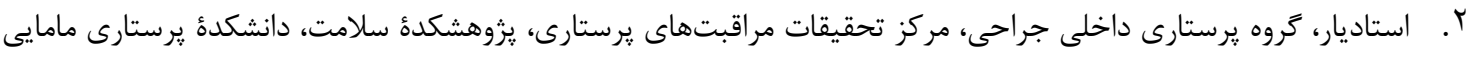

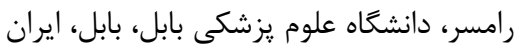

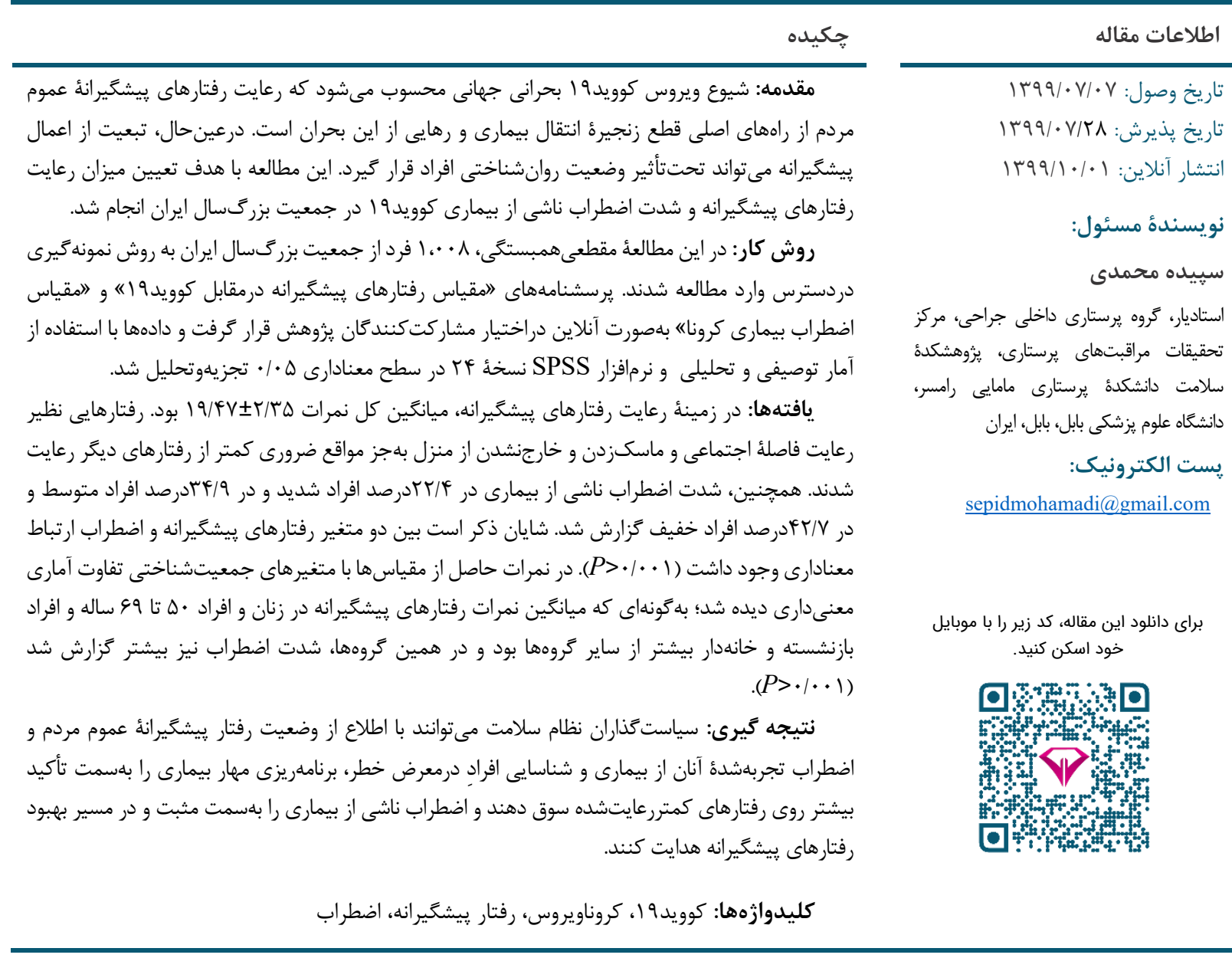

كشورهايى بود كه بيمارى كوويد9 ا در آن شيوع يافت و

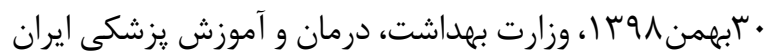

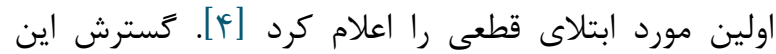

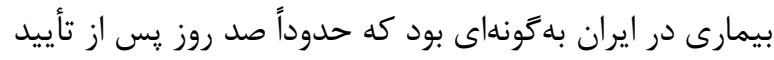

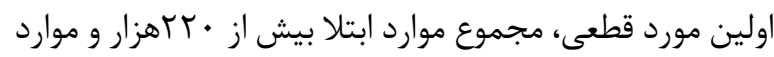
فوتى بيش از • اهزار مورد اعلام شد [ه]. باتوجهبه ماهيت مبهلم اين ويروس و قدرت درخورتوجه انتقال و نبود واكسن و درمان اختصاصى، مهمترين و درواقع
بيمارى كوويد9 كروناويروسهاست كه اولينبار در شهر ووهان، واقع در استان هوبى كشور جين، شناخته شد و از آنجا به ساير كشورهاى جهان شيوع ييدا كرد [1]]. اين ويروس با شدت انت انتقال قدرتمندش بلهسرعت سراسر جهان را فراگرفت و سازمان بهداشت جهانى (WHO) تنها حدود جهار ماه يس از تأييد اين ويروس در كشور جين، وضعيت پاندمى يا عالمَّير را در جهان

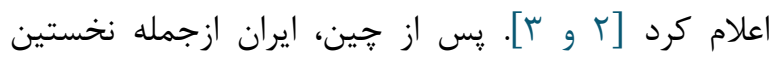


است و انسانها در استرسهاى طولانى شايد بلسمت خستگى

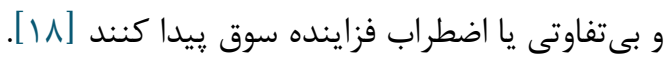

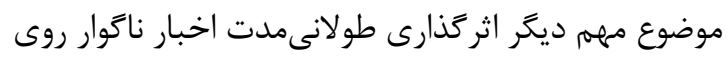

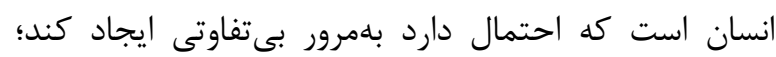

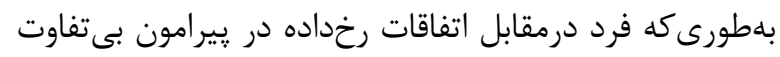

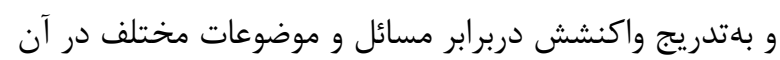

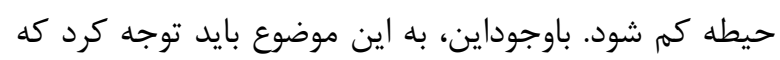

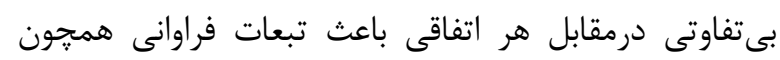
ازبينرفتن حس مسئوليتيذيرى در جامعه درقبال اتفاقات درات

مختلف خواهد شد [19] باتوجهبه وضعيت موجود، اينطور بهنظر مىرسد كه مقابله

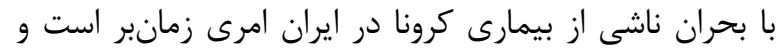

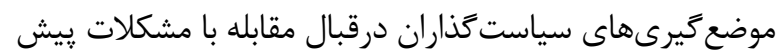

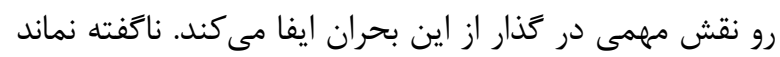

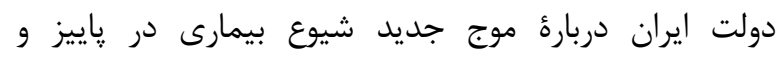

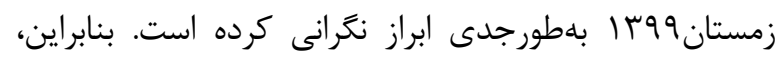

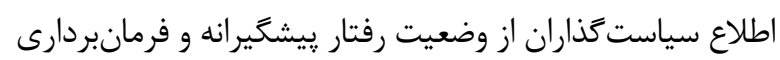
اجتماعى عموم مردم و استرسهاى تجربهشده آنان از بيمارى در موج اول براى برنامهريزىهاى دقيق بلمنظور مهار بيمارى

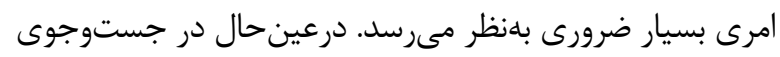
محققان، مطالعهاى يافت نشد كه ميزان رعايت رفتار بيشكيريرانه عموم مردم و اضطراب آنان در موج اول بيمارى را سنجيده باشداء

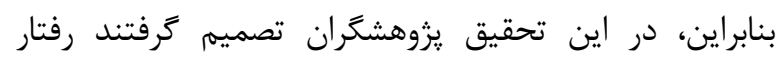

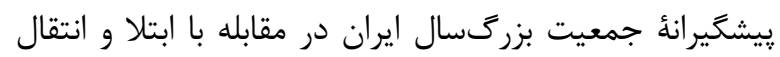
بيمارى كوويد9 ا و ميزان اضطراب دركشده آنان از اين بيمارى را بررسى كنند و ارتباط اين دو متغير را باهم بسنجند.

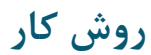

يزوهش حاضر، يزوهشى توصيفى همبستى بود كه روى

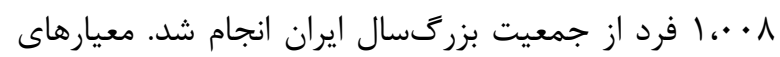

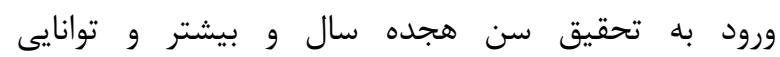
خواندنونوشتن به زبان فارسى و دسترسى به به شبكه آهاى اجتماعى رايج در ايران بود. شايان ذكر است آن دسته آندان

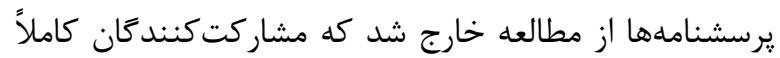

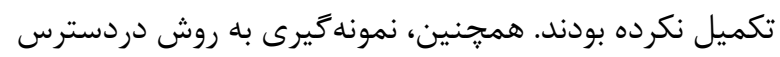

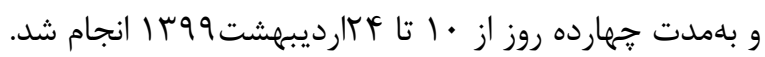

اصلى ترين راه كنترل بيمارى ازبينبردن زنجيره انتقال ويروس

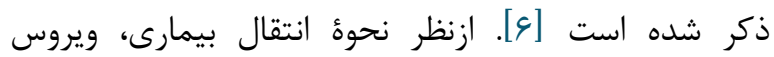
كوويد9 1 مىتواند ازطريق قطرات تنفس أنسى كه با سرفه يا بازدم

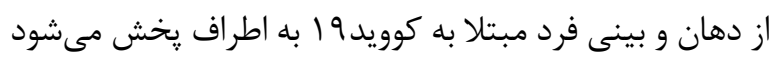

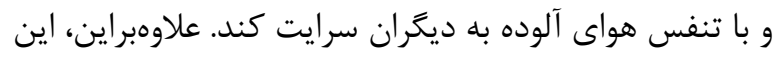

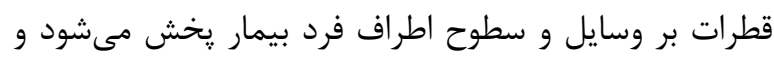

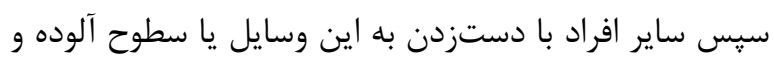

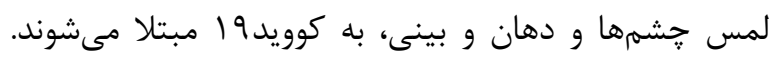

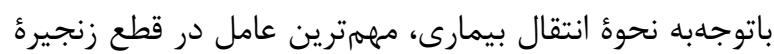

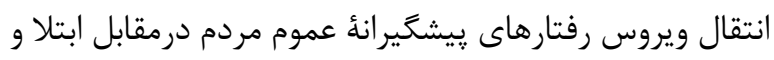

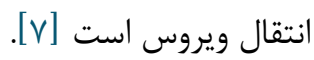
همسو با هشدارهاى جهانى در قطع زنجيرء انتقال، دولت

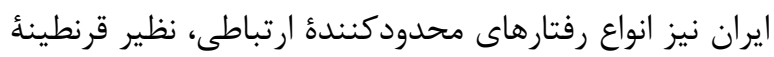

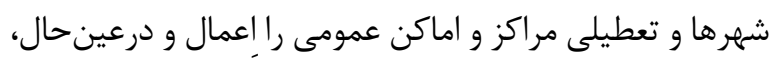

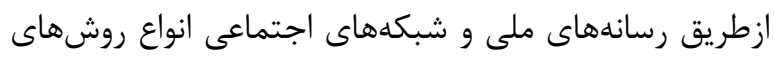

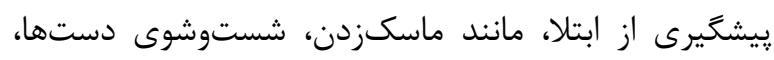

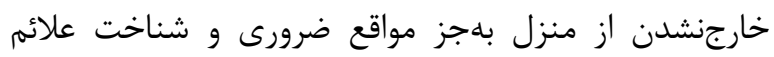

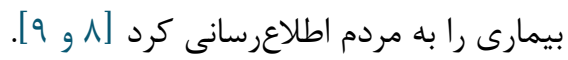

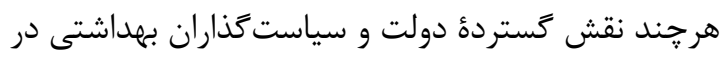

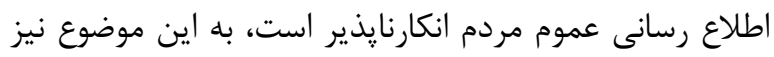

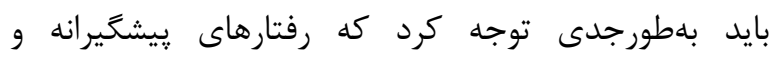

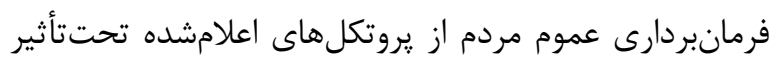

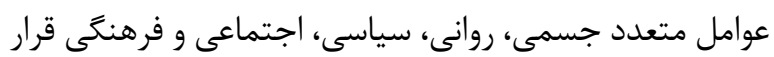

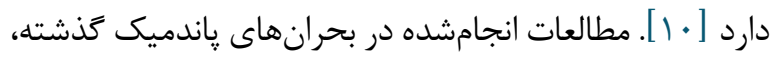
همجون بيمارى آنفولانزا و سارس نشان داده است كه عواملى دانى

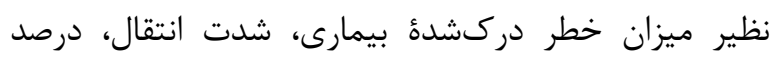

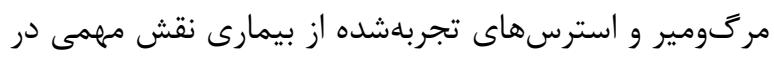

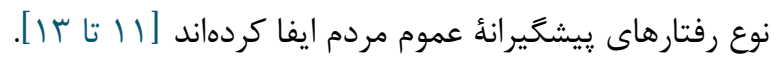

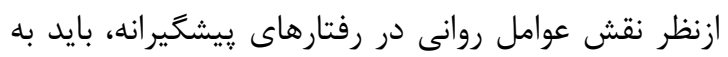

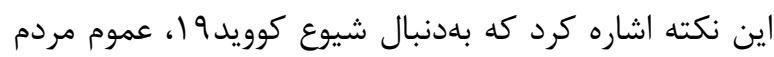

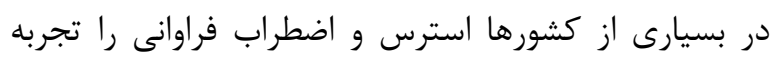

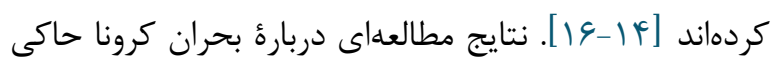

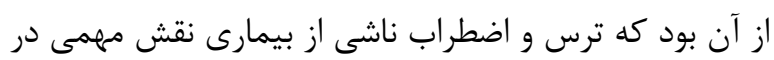

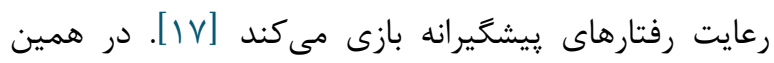

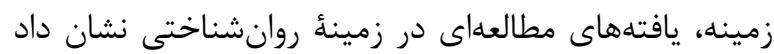

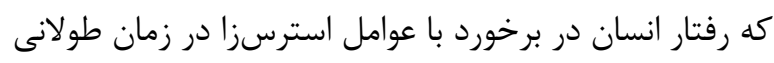

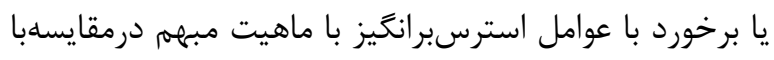

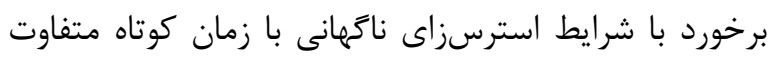


بلهنظور روايى محتوا، يرسشنامه به هشت عضو هيئتعلمى دانشگًاه علوم يزشكى و سه متخصص عفونى داده و يس از بررسى گويهها، تغييرات خواستهشده آنان اعمال شد. براى روايى صورى، :يرسشنامه دراختيار سى نفر از جمعيت يروسي بزرگسال ايرانى قرار گرفت و از اين طريق ميزان فهمه و دشوارى گويهها ارزيابى شد. بهمنظور يايايى نيز، همسانى

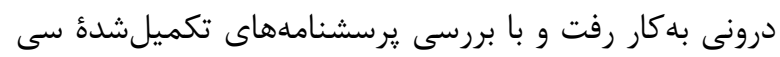

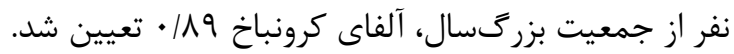
Corona Disease ( مقياس اضطراب بيمارى كرونا ابزارى براى سنجش اضطراب ناشى از شيوع (Anxiety Scale ويروس كرونا در كشور ايران است كه Alipour و همكاران تهيه و روايى و پايايى آن را تأييد كردهاند. اين ابزار هجده گويه دارد كه با مقياس جهاردرجهاى ليكرت شامل

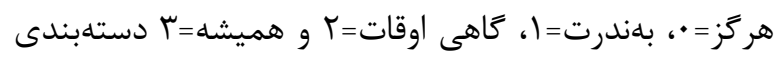
شده است. در اين مقياس، شدت اضطراب بدينترتيب تعريف

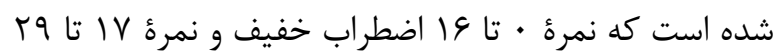
اضطراب متوسط و نمرؤ .ب تا عاه اضطراب شديد را نشان

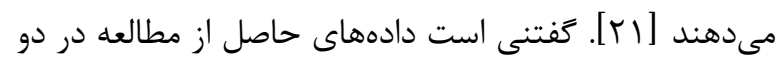

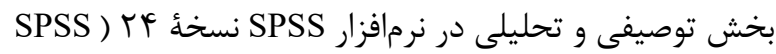
(Inc., Chicago, IL., USA

\section{ملاحظات اخلاقى}

يزوهش حاضر در كميتأ اخلاق دانشعاه علوم يزشكى بابل و كميتهٔ اخلاق ملى در يزوهشهاى زيست يزشكى با شماره

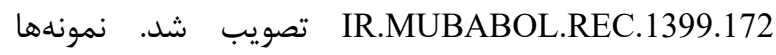
داوطلبانه در مطالعه شركت كردند و اختيار تكميلنكردن يرسشنامه به آنان داده شد. اهداف تحقيق در ابتداى برسشنامه به مشاركت كنند الكترونيك كرفته شد. همجنين، رعايت اصل رازدارى و امانت از ديخر اصول اخلاقى رعايتشده در اين مطالعه بود.

\section{يافته ها}

هنگًام نمونه جمعآورى شد كه 199 يرسشنامه بهدليل نقص در يرشدن از

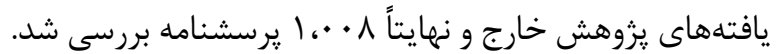
يافتههاى حاصل از دادههاى جمعيتشناختى حاكى از آن بود كه س/ع باعرصد مشاركت كنند

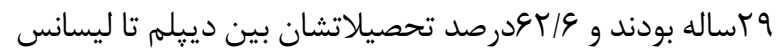

روش كار بدينترتيب بود كه پس از تصويب طرح تحقيقاتى حاضر در كميتأ اخلاق دانشعاه علوم يزشكى بابل، يرسشنامهها بعد از روايى و پايايى بهصورت آنلاين تهيه شدند و سيس لينك يرسشنامه در شبكههاى اجتماعى رايج در ايران، نظير واتساب و تلخرام قرار گرفت. از افراد حاضر در گروههاى شبكههاى اجتماعى يادشده خواسته شد ضمن تكميل يرسشنامه، آن را براى دوستان و آشنايانشان ارسال كنيند. يزوهشگران براى نمونه گيرى مطالعه سعى كردند باتوجهبيه

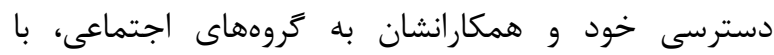
هدفهاى مختلف همجون آموزشى، تحصيلى، تفريحى،

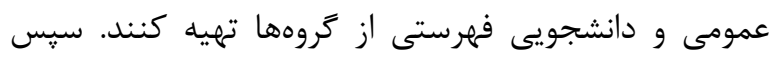
لينك يرسشنامه به گرووهايى ارسال شد كه طيف متعددى از

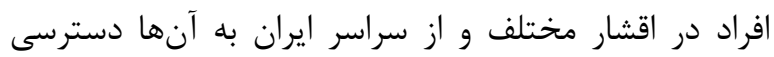
داشتند. اين كار منجر شد نمونهها نه بهطوركامل، بلكه باطورنسبى معرف عموم مردم ايران باشند.

\section{ابزارهاى اندازهَيرى}

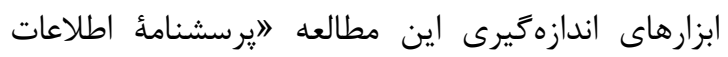
جمعيتشناختى" و "مقياس رفتارهاى ييشخيرانه درمقابل كوويد9 () و "امقياس اضطراب بيمارى كروناه بود. يرسشنامئ اطلاعات جمعيتشناختى از مواردى نظير سن، جنس، سطح تحصيلات و شغل تشكيل مىشد.

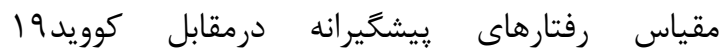
محققساخته بود كه باتوجهبه معيارها و اصول ارائهشده سازمان

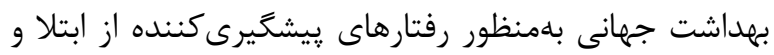

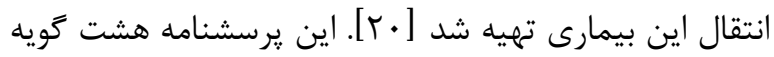

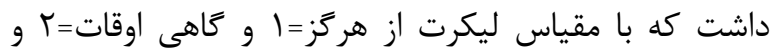

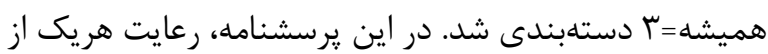
رفتارهاى ييشخيرانه در طيف هميشه و گاهى اوقات و هر زئز سنجيده شد. كمترين ميزان نمره حاصل از مقياس رفتارهاى

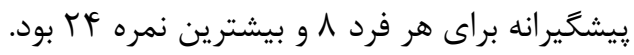

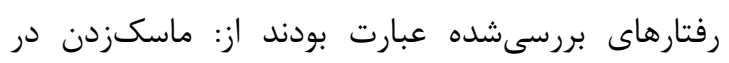

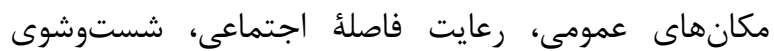
دستها حداقل براى بيست ثانيه، يوشاندن دهان و بينى حين عطسه و سرفه، شستن يا ضدعفونى كردن وسايل خريدشده، شركتنكردن در مهمانى و مجالس، خارجنشدن از منزل بهجز مواقع ضرورى و بهحداقلرساندن رفتوآمد با وسايل نقليئ عمومى. 


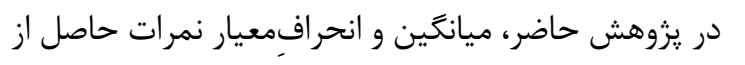

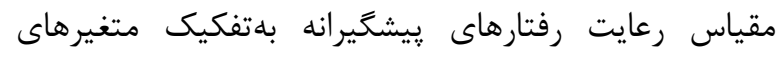

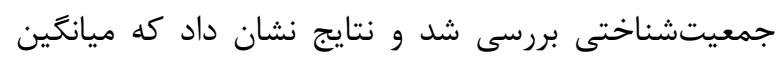

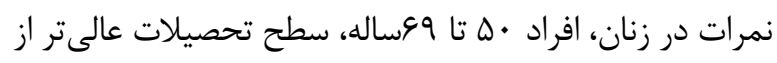

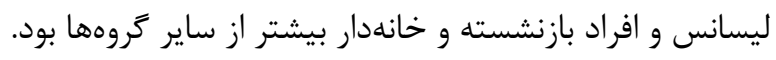
كفتنى است در تمام متغيرهاى جمعيتشناختى ارزيابىشدانده،

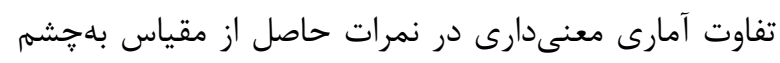

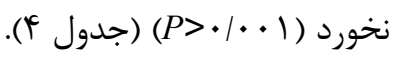

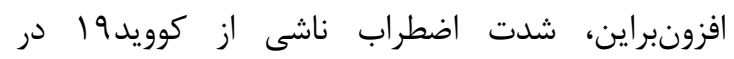

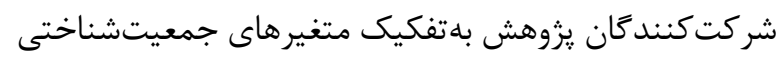

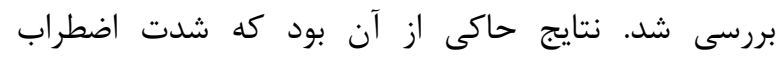

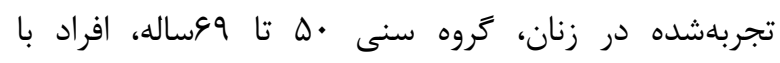

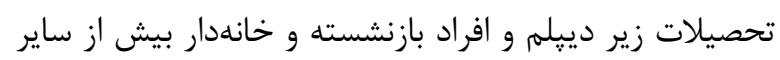

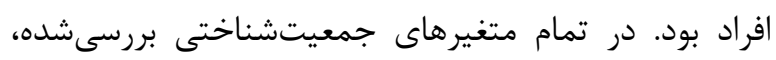

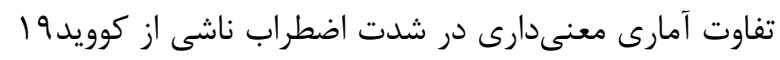

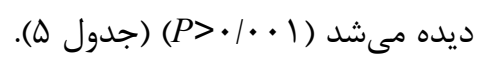

بود و N/Vادرصد نيز دانشجو بودند (جدول ()). در زمينأ رعايت

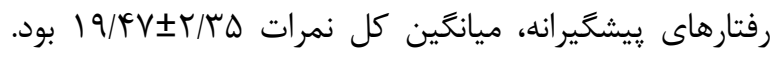

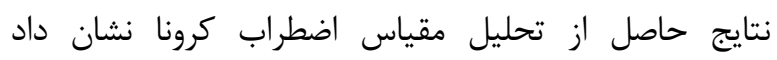
Tr/F

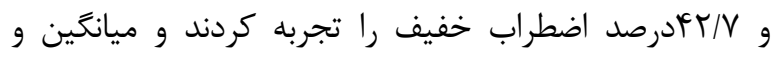

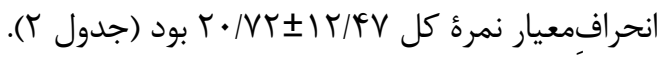

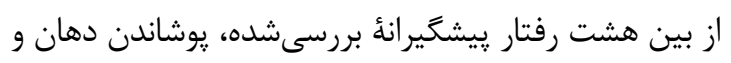

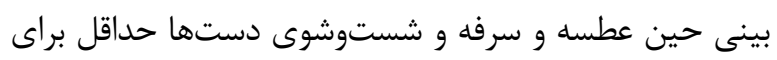

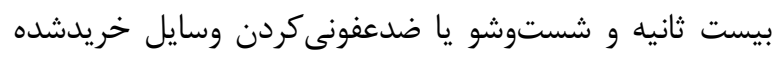

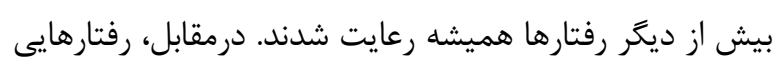

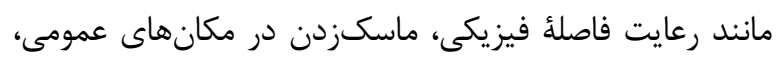

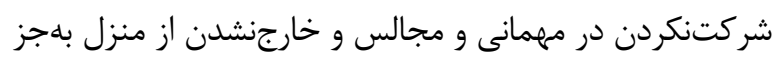

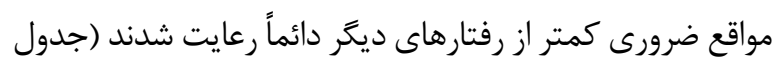

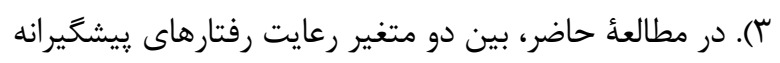

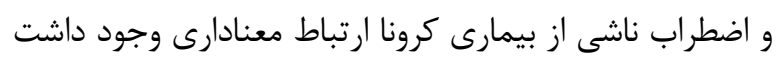

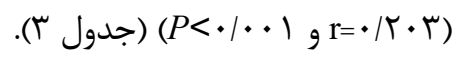

جدول ا. مشخصات جمعيتشناختى مشاركت كنندگًان يثوهش

\begin{tabular}{|c|c|c|c|}
\hline درصد & فراوانى & & \\
\hline $99 / \pi$ & 991 & زن & \multirow{2}{*}{ جنس } \\
\hline 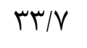 & ry. & مرد & \\
\hline$\Delta V / V$ & $\Delta \wedge T$ & 1 ا تا وץ & \multirow{4}{*}{ سن به سال } \\
\hline rN/T & rAd & fq تا r. & \\
\hline$r / Q$ & rd & 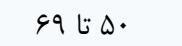 & \\
\hline$\cdot 19$ & 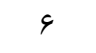 & • V و بزرت & \\
\hline$r \& / 0$ & r\&A & كارمند & \multirow{6}{*}{ شغل } \\
\hline$I T / T$ & שrו & شغل آزاد & \\
\hline rN/V & rq. & دانشجو & \\
\hline $1 / 1$ & 11 & بازنشسته & \\
\hline $19 / V$ & 191 & خانهدار & \\
\hline$F / \Lambda$ & Fᄉ & بيكار & \\
\hline$V / Q$ & Ve & زير دييلم & \multirow{3}{*}{ سطح تحصيلات } \\
\hline GT/G & إl & دييلم تا ليسانس & \\
\hline$r q / 4$ & ५१९ & عالىتر از ليسانسر & \\
\hline
\end{tabular}


جدول ז. نمرء كل و شدت اضطراب ناشى از كوويد19 و رعايت رفتار يِيشخيرانه بههمراه ارتباط ميان اين دو متغير

\begin{tabular}{|c|c|c|c|c|c|c|}
\hline \multicolumn{2}{|c|}{ اضطراب ناشى از كوويد19 } & & شدت & \multirow{2}{*}{\multicolumn{2}{|c|}{ 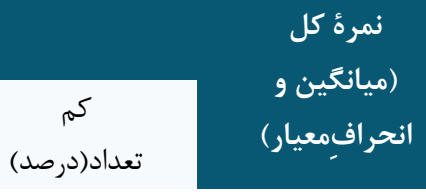 }} & \\
\hline P-value & $\mathrm{r}$ & تعداد(درصد) شديد & تعداد(درصد) متوسط) & & & \\
\hline \multirow{2}{*}{$P>\cdot / \cdot$} & \multirow{2}{*}{$\cdot / r \cdot r$} & $(Y T / Y) Y T G$ & $(r F / q) r \Delta Y$ & $(F T / V) F r$. & $r \cdot / V T \pm I T / F V$ & اضطراب ناشى از \\
\hline & & & & & $19 / \Psi \mathscr{E} \pm r / r \Delta$ & رِيش رِيت رفتارهاى \\
\hline
\end{tabular}

جدول r. ميزان رعايت رفتارهاى بيشعَيرانه مشاركتكنندكان يخوهش درمقابل كوويد19

\begin{tabular}{|c|c|c|c|c|c|c|}
\hline \multicolumn{2}{|c|}{ 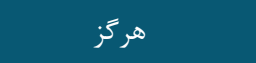 } & \multicolumn{2}{|c|}{ كَاهى اوقات } & \multicolumn{2}{|c|}{ هميشه } & \multirow{2}{*}{ رفتارهاى بيشخيرانه درمقابل كوويد919 } \\
\hline 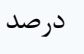 & فراوانى & 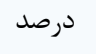 & فراوانى & ل مرصد & فراوانى & \\
\hline 9 & 91 & $r F / l$ & myF & $\Delta \& / V$ & $\Delta V T$ & ماسكزدن در مكانهاى عمومى \\
\hline r & $r \cdot$ & $\lceil\wedge / \Delta$ & $4 \wedge 9$ & $\forall N / D$ & $4 \wedge 9$ & رعايت فاصله فيزيكى \\
\hline$r / 9$ & rq & $r$ r/Q & rt人 & $V F / \Delta$ & $V \Delta I$ & شستوشوى دستها حداقل براى بيست ثانيه \\
\hline $1 / r$ & ir & $|F /|$ & IFT & $\Lambda F / \vee$ & $\Lambda \Delta F$ & يوشاندن دهان و بينى حين عطسه و سرفه \\
\hline$F / \Lambda$ & $\forall \wedge$ & $r F / 9$ & TFA & $v \cdot 19$ & VIr & شستن يا ضدعفونى كردن وسايل خريدشده \\
\hline $1 r / 9$ & $1 \mu$. & rN/T & 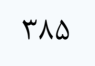 & F $/ 9$ & pqr & شركتنكردن در مهمانى و مجالس \\
\hline$r q / 1$ & rqu & $\varphi \Delta / F^{\mathcal{F}}$ & 909 & $\Delta / 9$ & $\Delta \varphi$ & خارجنشدن از منزل بهجز مواقع ضرورى \\
\hline$\varepsilon / \Gamma$ & GT & $r \cdot 19$ & $r \cdot \Lambda$ & $\varepsilon r / r$ & gru & بهحداقلرساندن رفتوآمد با وسايل نقليئ عمومى \\
\hline
\end{tabular}

جدول f. ميانغين و انحرافِمعيار نمرات مقياس رعايت رفتارهاى بِيشَيرانه به تفكيك متغير هاى جمعيتشناختى

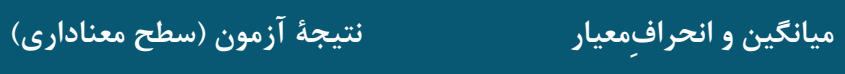

\begin{tabular}{|c|c|c|c|}
\hline \multirow{2}{*}{$P>\cdot \mid \cdot \cdot 1$} & $19 / \Lambda F \pm r / / \Lambda$ & زن & \multirow{2}{*}{ جنس } \\
\hline & $\mid \Lambda / V F \pm r / \Delta$. & مرد & \\
\hline \multirow{4}{*}{$P>\cdot / . .1$} & $19 / \cdot \Lambda \pm r / Y \wedge$ & 1 \تا وجr & \multirow{4}{*}{ سن به سال } \\
\hline & 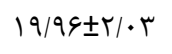 & rq تا r r & \\
\hline & $r \cdot \mid \Delta V \pm r / \cdot r$ & •ه اه & \\
\hline & $\mid N / \& 9 \pm \Gamma / 9 D$ & •V و بزرگتر & \\
\hline
\end{tabular}




\begin{tabular}{|c|c|c|c|}
\hline \multirow{3}{*}{$P>\cdot \mid \cdot \cdot 1$} & $19 / \cdot r \pm r / r F$ & زير دييلم & \multirow{3}{*}{ سطح تحصيلات } \\
\hline & $19 / \cdot r \pm r / r \mid$ & ديِلم تا ليسانس & \\
\hline & $19 / 9 Y \pm r / 11$ & عالىتر از ليسانس & \\
\hline \multirow{6}{*}{$P>\cdot 1 \cdot \cdot 1$} & $19 / 9 \wedge \pm r / 19$ & كارمند & \multirow{6}{*}{ شغل } \\
\hline & $\mid N / 9 V \pm r / 9 \Delta$ & شغل آزاد & \\
\hline & $19 / 1 f \pm r / r \Delta$ & دانشجو & \\
\hline & $r \cdot / V T \pm I / I$. & بازنشسته & \\
\hline & $r \cdot / 11 \pm 1 / q$. & خانهدار & \\
\hline & $1 \Lambda / \Lambda r \pm r / 99$ & بيكار & \\
\hline
\end{tabular}

جدول ه. شدت اضطراب ناشى از كوويد91 در مشاركت كنندگًان يزوهش بهتفكيك متغير هاى جمعيتشناختى

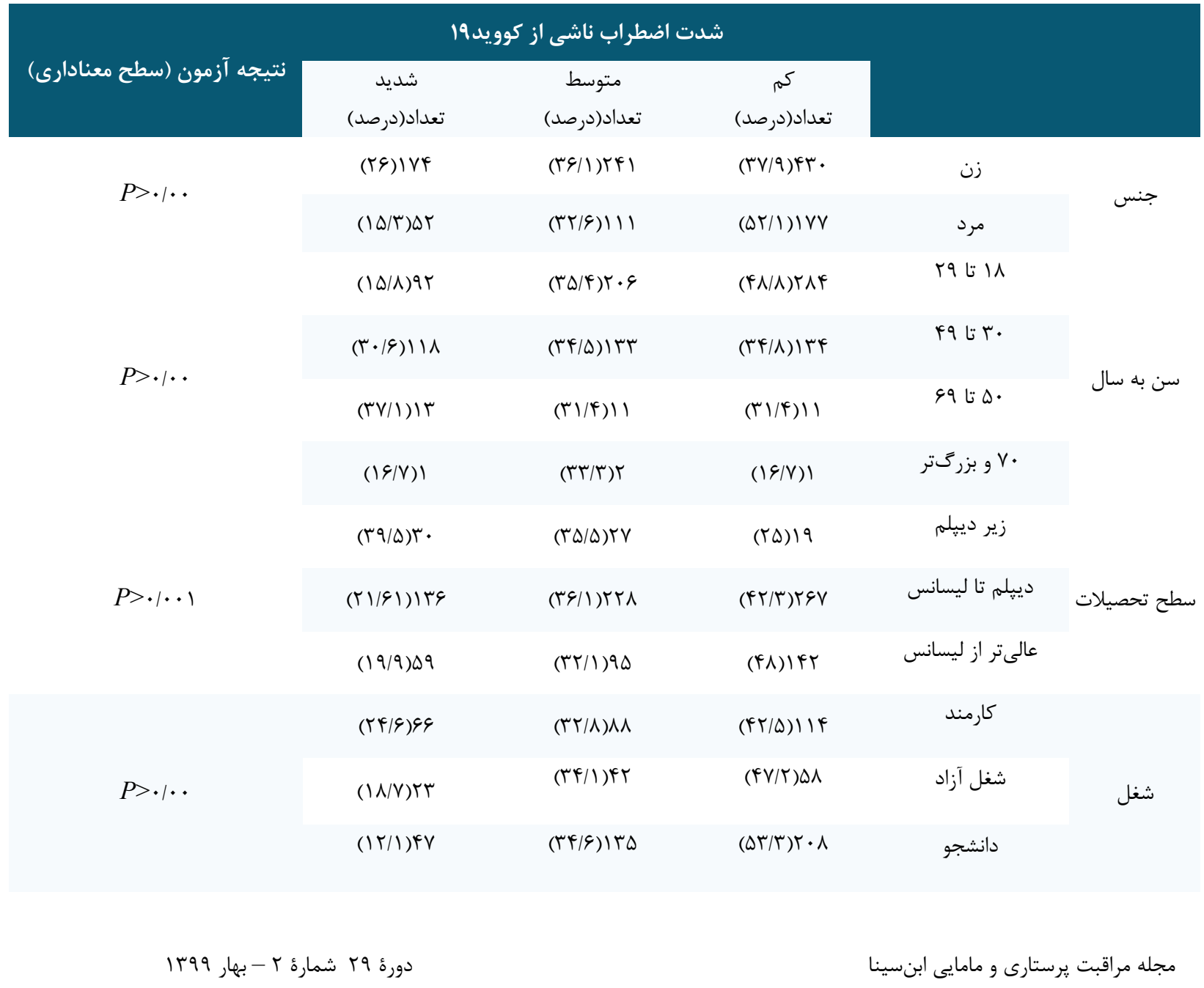




\begin{tabular}{|c|c|c|c|c|}
\hline \multicolumn{4}{|c|}{ شدت اضطراب ناشى از كوويد19 } & \\
\hline \multirow[t]{2}{*}{ نتيجه آزمون (سطح معنادارى) } & شديد & متوسط & كم & \\
\hline & تعداد(درصد) & تعداد(درصد) & تعداد(درصد) & \\
\hline & $(\uparrow \Delta / \Delta) \Delta$ & $(r V / \Gamma) \Gamma$ & $(T V / T) r$ & بازنشسته \\
\hline & $(F F / \varepsilon) \vee Q$ & $(ץ q / \Gamma) \varsigma \varphi$ & $(19 / 1) Y V$ & خانهدار \\
\hline & $(Y \cdot \mid \Lambda))$. & $(\Gamma \vee / \Delta) \backslash \Lambda$ & $(\xi \backslash / V) r$. & بيكار \\
\hline
\end{tabular}

اساسى در رعايت رفتارهاى ييشگيرانه ايفا مى كند [بr].

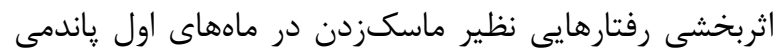

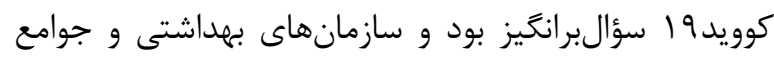
مختلف با اين مسئله ضدونقيض برخورد كردند؛ بنابراين، آنها

را مىتوان ازجمله دلايل ضعف در اين حيطه دانست.

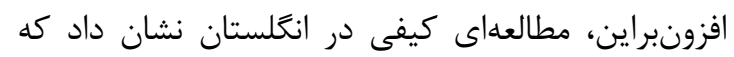
وجود امكانات كافى با هزينه كم در بهبود رعايت رفتارهاى دئي ييشخيرانه در دوران ياندمى بسيار مؤثر است و در دوران بروز

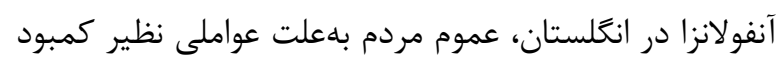
ماسك و مواد ضدعفونى كننده و نبود فضاى كافى براى اجراى فاصله فيزيكى در رعايت رفتارهاى بيشخيرانه با مشكل مواجه

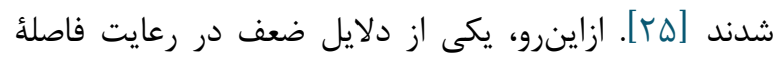
اجتماعى و ماسكزدن در مكانهاى عمومى يزوهش حاضر

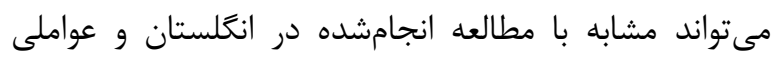

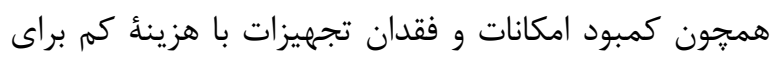
استفاده عموم مردم در دوران ابتدايى شيوع بيمارى باشد. تجزيهوتحليل دادهها درزمينـ اضطراب ناشى از كوويد 19

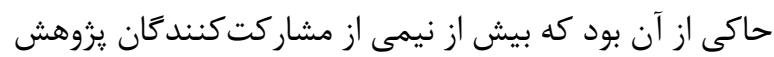

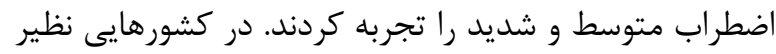
جين، هند، عمان و ايران، مطالعات متعددى وضعيت

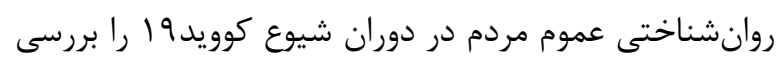
و به افزايش سطح استرس و اضطراب و يريشانى مردم در اين

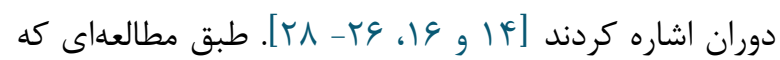
در ماه اول ورود كوويد9 إنه ايران انجام شد، ميزان اضطراب تجربهشده عموم مردم ايران در سطح بالا و متوسط بود و از

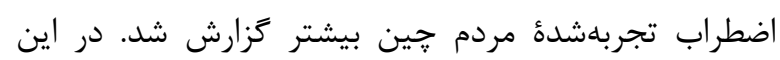
تحقيق، عواملى نظير سطح حمايت اجتماعى ازجمله دلايل

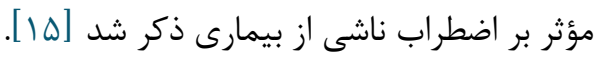

تجزيلهوتحليل دادههاى مطالعه نشان داد كه رعايت

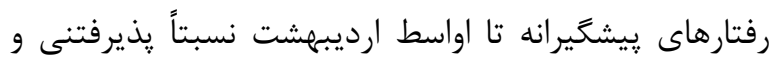

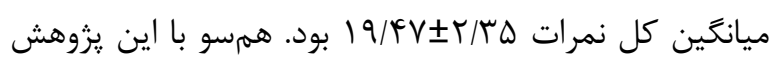
در ايالات متحده آمريكا، مطالعهاى تبعيت عموم مردم از رفتارهاى بيشخيرانه در هفتأ اول بيمارى همه گيرى كوويد 19

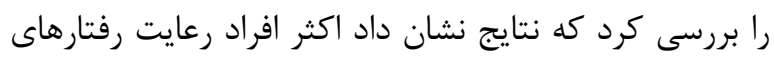

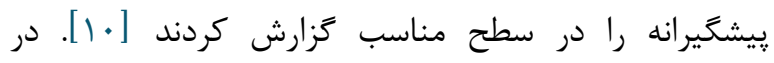

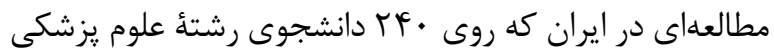

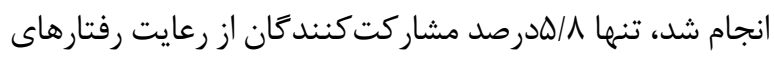
ييشگيرانه نمره كم كسب كردند و محققان مطالعه ازجمله تنها دلايل اين مسئله را سطح سواد و آكاهى بيشتر اين گرووه ذكر كردند [بr] برخلاف نتايج تحقيق حاضر، مطالعهاى در ميانمار حاكى

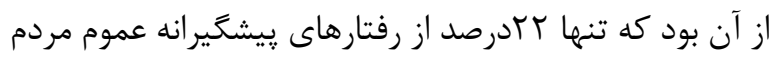
در سطح يذيرفتنى بود و هأدرصد از شركت كنند دست خود را شستوشو مى دادند و لأدرصد از آنان هميشه هنگًام عطسه يا سرفه دهان و بينى را مى ريوشاندند و تننها Fسادرصد از مسافرت خوددارى مى كردند. در اين يزوهش، ئى

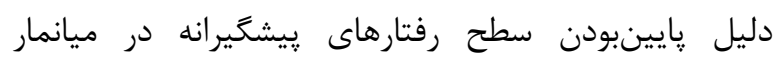

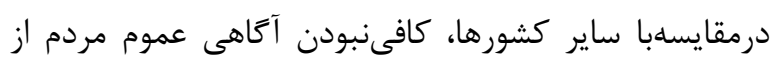
كروناويروس در اين كشور ذكر شد [سب].

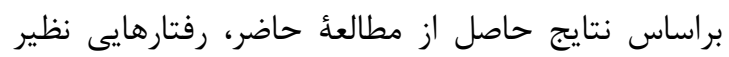
رعايت فاصله اجتماعى، ماسكزدن در مكانهاى عمومى، شركتنكردن در مهمانى و مجالس و خارجنشدن از منزل بهجز ماسئ مواقع ضرورى كمتر از ساير رفتارها هميشه رعايت شدند. در

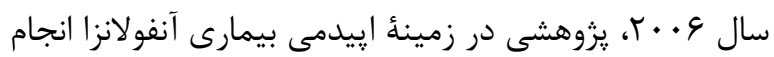

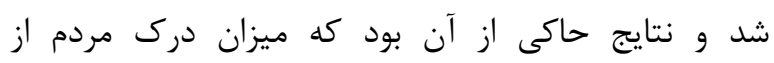
اثربخشبودن رفتار ييشخيرانه در مبتلانشدن به بيمارى نقش ان 
ييشنهاد مىشود در مطالعات آتى روشى اتخاذ شود كه حضور متناسب افراد سالمند مدنظر قرار زيرد.

$$
\text { نتيجه گَيرى }
$$

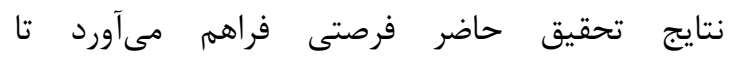
سياست گذاران نظام سلامت با نگاهى بر ميزان رعايت رفتارهاى ييشخيرانهٔ عموم مردم در مقابله با بيمارى كوويد9 او

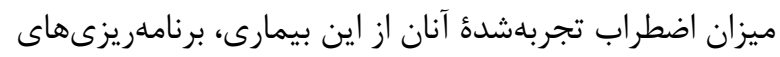

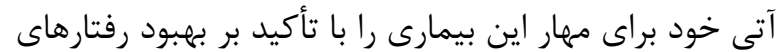
كمتررعايتشده مردم سوق دهند. همجنين، از آنجاكه اضطراب تجربهشده عموم مردم در حد متوسط و شديد بود، انتظار مىرود سياست گذاران با هدايت اضطراب ناشى از بيمارى بهسمت مثبت و در مسير بهبود رفتارهاى ييشخيرانه، از بروز خستخى و اختلالات ناشى از اضطرابهاى مزمن در دوران بروز

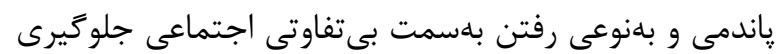
كنند.

\section{سياسگزارى}

اين مطالعه حاصل طرح مصوّب در كميتهٔ تحقيقات

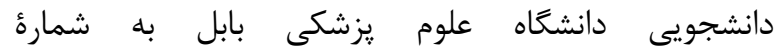

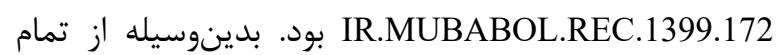
مسئولان دانشعاه علوم يزشكى بابل كه در تصويب اين طرح

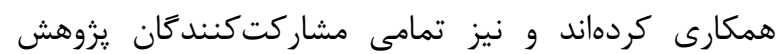
قدردانى مى كنيم.

$$
\text { تعارض در منافع }
$$

بين نويسندكان هيج گونه تعارضى در منافع وجود ندارد

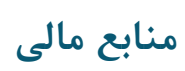

منابع مالى اين مطالعه توسط نويسندكان تامين شده است.

\section{References}

1. Cascella M, Rajnik M, Cuomo A, Dulebohn SC, Di Napoli R. Features, evaluation and treatment coronavirus [COVID19]. StatPearls Publishing; 2020.
در مطالعُ حاضر، بين دو متغير رعايت رفتارهاى ييشخيرانه و اضطراب ناشى از بيمارى كوويد9 1 ارتباط معنادارى وجود

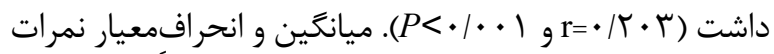
حاصل از مقياس رعايت رفتارهاى بيشخَيرانه و شدت اضطراب

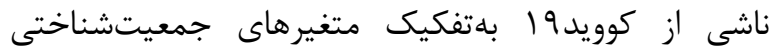

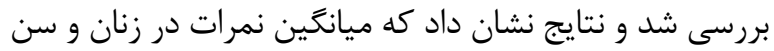
•ه تا و9 سال و افراد بازنشسته و خانهدار بيشتر از ساير زروهها بود و در همين گروههاى جمعيتشناختى، شدت اضطراب نيز

$$
\text { بيشتر ارزيابى شد. }
$$

همسو با يروهش حاضر، مطالعهاى در انگلستان به نقش إنش

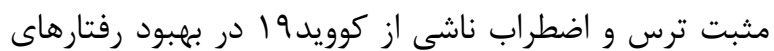
ييشخيرانه نظير شستن دست و رعايت فاصله اجتماعى اشاره كرد. نويسند

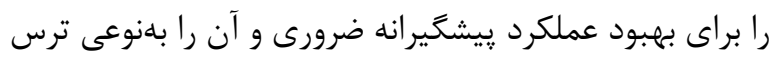
و اضطراب مؤثر و عملكردى دانستند؛ اما تذكر دادند كه تجربئ ترس و اضطراب ناشى از بيمارى در طولانىمدت ممكن است

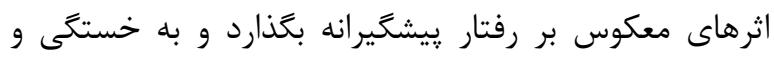

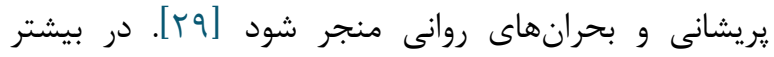

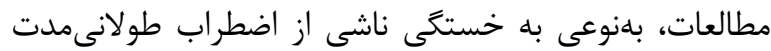
بهعنوان عامل مؤثر در رعايتنكردن رفتار پيشخيرانه اشاره بهاب

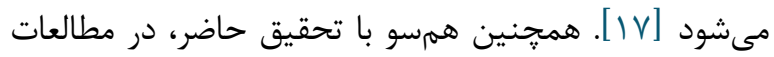
متعدد انجامشده در دوران پاندمى در كشورهاى گوناگون نتايج

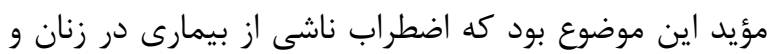

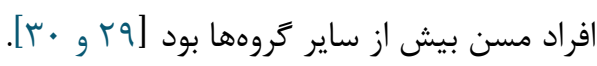

\section{محدوديتهاى يثورهش}

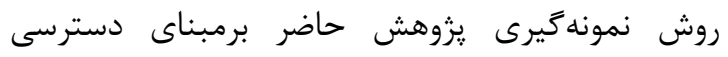

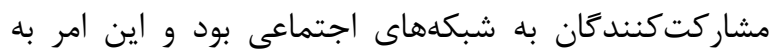
تناسبنداشتن ورود نمونهاى يزوهش براساس متغيرهاى جمعيتشناختى مانند سن منجر شد. ازآنجاكه تعداد افراد سالمند مشاركتكننده در يزوهش از جوانان كمتر بود،

2. Organization WHO. Coronavirus disease 2019 [COVID19]: situation report, 72. 2020. [Available from: https://www.who.int/emergencies/diseases/novelcoronavirus-2019/situation-reports. Accessed May 23, 2020 
اميرمالك نخعى زاده و سيیده محمدى 199

3. Spinelli A, Pellino G. COVID-19 pandemic: perspectives on an unfolding crisis. Br J Surg. 2020 Mar 19. [DOI:10.1002/bjs.11627] [PMID] [PMCID]

4. Kim PS, Reicin AS. Discontinuation of VIOXX. The Lancet. 2005 Jan 1;365(9453):23. [DOI:10.1016/S01406736(04)17652-6]

5. worldmeter. Coronavirus Cases in Iran 2020 [Available from:

https://www.worldometers.info/coronavirus/country/iran/ Accessed May 24, 2020

6. Bai Y, Yao L, Wei T, Tian F, Jin D-Y, Chen L, et al. Presumed asymptomatic carrier transmission of COVID19. Jama. 2020;323[14]:1406-7. [DOI:10.1001/jama.2020.2565] [PMID] [PMCID]

7. Hellewell J, Abbott S, Gimma A, Bosse NI, Jarvis CI, Russell TW, et al. Centre for the Mathematical Modelling of Infectious Diseases COVID-19 Working Group. Funk S, Eggo RM. Feasibility of controlling COVID-19 outbreaks by isolation of cases and contacts. Lancet Glob Health. 2020 Apr; 8 (4): e488-e496. [DOI:10.1016/S2214109X(20)30074-7]

8. Tuite AR, Bogoch II, Sherbo R, Watts A, Fisman D, Khan K. Estimation of coronavirus disease 2019 (COVID-19) burden and potential for international dissemination of infection from Iran. Ann Intern Med. 2020 May 19;172(10):699-701. [DOI:10.7326/M20-0696] [PMID] [PMCID]

9. Zandifar A, Badrfam R. Iranian mental health during the COVID-19 epidemic. Asian J Psychiatr. 2020 Mar;51. [DOI:10.1016/j.ajp.2020.101990] [PMID] [PMCID]

10. Wise T, Zbozinek TD, Michelini G, Hagan CC. Changes in risk perception and protective behavior during the first week of the COVID-19 pandemic in the United States.

11. Lau JT, Kim JH, Tsui H, Griffiths S. Perceptions related to human avian influenza and their associations with anticipated psychological and behavioral responses at the onset of outbreak in the Hong Kong Chinese general population. American Journal of Infection Control. 2007 Feb 1;35(1):38-49. [DOI:10.1016/j.ajic.2006.07.010] [PMID] [PMCID]

12. Lau JT, Yang X, Tsui H, Kim JH. Monitoring community responses to the SARS epidemic in Hong Kong: from day 10 to day 62. J Epidemiology Community Health. 2003 Nov 1;57(11):864-70. [DOI:10.1136/jech.57.11.864] [PMID] [PMCID]

13. Lau JT, Tsui H, Kim JH, Griffiths S. Perceptions about status and modes of H5N1 transmission and associations with immediate behavioral responses in the Hong Kong general population. Prevent Med. 2006 Nov 1;43(5):40610. [DOI:10.1016/j.ypmed.2006.06.007] [PMID]

14. Huang Y, Zhao N. Generalized anxiety disorder, depressive symptoms and sleep quality during COVID-19 outbreak in China: a web-based cross-sectional survey. Psychiatry research. $2020 \quad$ Apr $12: 112954$. [DOI:10.1016/j.psychres.2020.112954] [PMID] [PMCID]
15. Jahanshahi AA, Dinani MM, Madavani AN, Li J, Zhang SX. The distress of Iranian adults during the Covid-19 pandemic-More distressed than the Chinese and with different predictors. Brain Behav Immun. 2020 Jan 1. [DOI:10.1101/2020.04.03.20052571]

16. Naser AY, Dahmash EZ, Al-Rousan R, Alwafi H, Alrawashdeh HM, Ghoul I, Abidine A, Bokhary MA, ALHadithi HT, Ali D, Abuthawabeh R. Mental health status of the general population, healthcare professionals, and university students during 2019 coronavirus disease outbreak in Jordan: a cross-sectional study. medRxiv. 2020 Jan 1. [DOI:10.1101/2020.04.09.20056374]

17. Harper CA, Satchell LP, Fido D, Latzman RD. Functional fear predicts public health compliance in the COVID-19 pandemic. International journal of mental health and addiction. 2020 Apr 27. [DOI:10.1007/s11469-020-002815] [PMID] [PMCID]

18. Brosschot JF, Gerin W, Thayer JF. The perseverative cognition hypothesis: A review of worry, prolonged stressrelated physiological activation, and health. Journal of psychosomatic research. 2006 Feb 1;60(2):113-24. [DOI:10.1016/j.jpsychores.2005.06.074] [PMID]

19. Wenzel L, Glanz K, Lerman C. Stress, coping, and health behavior. Health behavior and health education. 2002 Sep 9;2:210-39.

20. Organization WH. Coronavirus disease [COVID-19] advice for the public 2020 [Available from: https://www.who.int/emergencies/diseases/novelcoronavirus-2019/advice-for-public. Accessed May 25, 2020

21. Alipour A, Ghadami A, Alipour Z, Abdollahzadeh H,. Preliminary validation of the Corona Disease Anxiety Scale [CDAS] in the Iranian sample. J Health Psycol. 7516;[32]8.2020. DOI: 10.30473/HPJ.2020.52023.4756

22. Taghrir MH, Borazjani R, Shiraly R. COVID-19 and Iranian Medical Students; A Survey on Their RelatedKnowledge, Preventive Behaviors and Risk Perception. Archives of Iranian medicine. 2020 Apr 1;23(4):249-54. [DOI:10.34172/aim.2020.06] [PMID]

23. Mya Kyaw S, Aye SM, Hlaing Win A, Hlaing Su S, Thida A. Awareness, perceived risk and protective behaviours of Myanmar adults on COVID-19. https://www. ijcmph. com/index. php/ijcmph/article/download/6308/3908. 2020. [DOI:10.18203/2394-6040.ijcmph20201530]

24. Rubin GJ, Amlôt R, Page L, Wessely S. Public perceptions, anxiety, and behaviour change in relation to the swine flu outbreak: cross sectional telephone survey. Bmj. $2009 \mathrm{Jul}$ 2;339:b2651. [DOI:10.1136/bmj.b2651] [PMID] [PMCID]

25. Morrison LG, Yardley L. What infection control measures will people carry out to reduce transmission of pandemic influenza? A focus group study. BMC public health. 2009 Dec 1;9(1):258. [DOI:10.1186/1471-2458-9-258] [PMID] [PMCID] 
19 ميزان رعايت رفتارهاى بيشََيرانه و اضطراب ناشى از بيمارى كوويد IV.

26. Meng H, Xu Y, Dai J, Zhang Y, Liu B, Yang H. Analyze the psychological impact of COVID-19 among the elderly population in China and make corresponding suggestions. Psychiatry Res. $2020 \quad$ Jul;289:112983. [DOI:10.1016/i.psychres.2020.112983] [PMCID]

27. Moghanibashi-Mansourieh A. Assessing the anxiety level of Iranian general population during COVID-19 outbreak. Asia J Psychiatry. 2020 Apr 18:102076. [DOI:10.1016/j.ajp.2020.102076] [PMID] [PMCID]

28. Roy D, Tripathy S, Kar SK, Sharma N, Verma SK, Kaushal V. Study of knowledge, attitude, anxiety \& perceived mental healthcare need in Indian population during COVID-19 pandemic. Asian Journal of Psychiatry. 2020 Apr 8:102083. [DOI:10.1016/j.ajp.2020.102083] [PMID] [PMCID]

29. Imtiaz A, Hossain MA, Khan NM. COVID-19 in Bangladesh: Measuring differences in individual precautionary behaviors among young adults. medRxiv. 2020 Jan 1. [DOI:10.1101/2020.05.21.20108704]

30. Bish A, Michie S. Demographic and attitudinal determinants of protective behaviours during a pandemic: A review. British journal of health psychology. 2010 Nov;15(4):797-824. [DOI:10.1348/135910710X485826] [PMID] [PMCID] 